\title{
BIOLOGIA REPRODUTIVA DE Acacia mearnsii DE WILD.: RECEPTIVIDADE DE ESTIGMAS ${ }^{1}$
}

\author{
Eudes Maria Stiehl-Alves² e Maisa Pimentel Martins ${ }^{3}$
}

\begin{abstract}
RESUMO - O objetivo deste trabalho foi analisar a receptividade de estigmas de Acacia mearnsii De Wild. em 20 árvores da Área de Produção de Sementes (APS) da Fazenda Locatelli, da empresa SETA S.A., no município de Butiá (RS) e comparar os períodos de receptividade de estigmas e de viabilidade polínica em diversas fases da abertura floral. Foi utilizado como método de colorimetria o reagente de Baker para indicar a receptividade e a viabilidade. As análises foram conduzidas em delineamento inteiramente casualizado e a estatística $\chi^{2}$ foi utilizada para verificar a significância dos eventos estudados. Foi observada receptividade no início da abertura floral (71\%), alcançando a total receptividade (100\%) em plena antese. A viabilidade polínica foi detectada no início da antese (77\%) e em total abertura floral (88\%). Na fase de senescência foram observados estigmas receptivos (50\%) e políades viáveis (23\%). Há sobreposição da fase de viabilidade masculina e de receptividade feminina, aumentando as chances de autopolinização. Na maioria das árvores analisadas (85\%) foi observada a total receptividade (100\%) nos estigmas amostrados. Em três árvores (15\%) observou-se uma média inferior a 95\% de estigmas receptivos. Não foi observada diferença significativa pelo teste do $\chi^{2}$ na receptividade dos estigmas no germoplasma analisado, sugerindo que o genótipo não interfere diretamente para a receptividade dos estigmas.
\end{abstract}

Palavras chave: acácia-negra, antese, polinização, germoplasma.

\section{REPRODUCTIVE BIOLOGY OF Acacia mearnsii DE WILD.: STIGMA RECEPTIVITY}

\begin{abstract}
The purpose of this study was to evaluate the stigma receptivity of Acacia mearnsii De Wild. in 20 trees of the Seed Production Area on the Fazenda Locatelli of the company SETA S.A., in the county of Butiá, state of Rio Grande do Sul, and to compare the periods of stigma receptivity and pollen viability at different stages of flower opening. The colorimetry method of the Baker reagent was used to determine receptivity and viability. The analyses were evaluated in a completely randomized design and the $\chi^{2}$ statistics were used to verify the significance of the studied events. The receptivity increased from the beginning of flower opening (71\%) to total receptivity (100\%) at full anthesis. Pollen viability was detected in the beginning of anthesis (77\%) and at total flower opening (88\%). Receptive stigmas (50\%) and viable polyads (23\%) were observed in the senescence stage. The phases of male viability and female receptivity were superposed, which increases the chances of self-pollination. Full receptivity (100\%) was observed in the sampled stigma of most evaluated trees (85\%). In three trees (15\%) receptive stigmas were in the mean below 95\%. No significant difference was detected by the $\chi^{2}$ test in the stigma receptivity of the germplasm under study, indicating that the genotype does not interfere directly with stigma receptivity.
\end{abstract}

Keywords: anthesis, black wattle, germplasm, pollination.

\footnotetext{
${ }^{1}$ Recebido em 06.12.2006 e aceito para publicação em 19.05.2008.

${ }^{2}$ ProgramadePós-Graduaçãoem GeomáticadaUniversidadeFederal deSantaMaria(UFSM), SantaMaria-RS.E-mail: <eudesmsalves@yahoo.com.br>.

${ }^{3}$ Departamento de Ciências Florestais da UFSM. E-mail: <lbfmaisa@smail.ufsm.br>.
} 


\section{INTRODUÇÃO}

Acacia mearnsii De Wild. (acácia-negra) é uma espécie arbórea com distribuição natural na Tasmânia e nas regiões sul e sudeste da Austrália que tem sido amplamente plantada em várias regiões do mundo. No Rio Grande do Sul, foi introduzida no início do século passado, sendo considerada uma espécie com amplo potencial econômico por sua múltipla utilidade na indústria de couros e produtos químicos (CALDEIRA et al., 2003; PAULINO et al., 2003; PERRANDO e MARTINS-CORDER, 2006). Embora a acácia-negra tenha se destacado no setor florestal, informações sobre a sua biologia reprodutiva são incipientes, impossibilitando a interferência em cruzamentos para obter indivíduos superiores.

O florescimento da acácia-negra no Rio Grande do Sul tem duração aproximada de quatro meses, no período de agosto até o mês de novembro (STIEHLALVES e MARTINS-CORDER, 2006). É ampla a abundância de insetos atraídos pelo forte odor de suas inflorescências. Estudos têm sugerido que um coleóptero, Macrodactylus suturalis, seja o principal agente de polinização das populações analisadas, embora Paula (2005) tenha identificado as abelhas Apis mellifera como principais vetores de polinização em APS's localizadas nas regiões de Triunfo, Piratini e Cristal (RS).

A estrutura floral da $A$. mearnsii é composta por inflorescências dispostas em racimos axilares. Cada inflorescência contém aproximadamente 50 flores que podem ser hermafroditas ou funcionalmente masculinas, de tonalidade amarela. A acácia-negra exibe a protoginia e a fase de receptividade feminina tem duração aproximada de 24 horas. A fase de viabilidade masculina tem início após a perda de receptividade dos estigmas e tem duração de aproximadamente três a cinco dias (GRANT et al., 1994).

Nas flores masculinas, o estigma pode ser ausente ou não-funcional. As flores hermafroditas apresentam um estigma hidrofílico com um ovário simples contendo 12 a 14 óvulos (KENRICK e KNOX, 1981; MONCUR et al., 1991). Nas espécies de Acacia, a superfície estigmática libera uma substância composta por proteínas, carboidratos e lipídeos (KENRICK e KNOX, 1981). De acordo com esses autores, polifenóis não foram observados nesse composto. A receptividade de estigmas em várias espécies tem sido analisada por meio de coloração citoquímica, a qual permite uma estimativa do período receptivo pela identificação através de cores de proteínas, carboidratos ou lipídeos presentes nesta fase. Informações sobre a receptividade de estigmas de A. mearnsii são desconhecidas.

Foi verificado em suas flores que a estrutura masculina é formada por anteras bilobadas localizadas terminalmente no filamento e cada lóbulo se encontra dividido em quatro lóculos pareados um acima do outro (KENRICK e KNOX, 1979). Cada lóculo contém uma estrutura em forma de disco biconvexo denominada políade, constituída por oito grãos-de-pólen dispostos no centro e oito grãos-de-pólen arranjados na periferia do disco, totalizando 16 grãos-de-pólen (GRANT et al., 1994). O total de grãos-de-pólen em cada antera é de 128 (KENRICK e KNOX, 1979; MONCUR et al., 1991; GRANT et al., 1994).

Estudos têm sugerido que, apesar da grande quantidade de grãos-de-pólen produzida pela acácianegra, a viabilidade não é expressiva, o que pode estar contribuindo para a produção insuficiente de sementes. Entre os métodos já testados para avaliar a viabilidade de políades de $A$. meanrsii encontra-se o reagente de Baker (RODRIGUEZ-RIANO e DAFNI, 2000). Essa solução tem sido utilizada tanto na análise da viabilidade polínica de diversas espécies vegetais (RODRIGUEZRIANO e DAFNI, 2000), quanto para verificar a receptividade estigmática (DAFNI e MAUÉS, 1998; MAUÉS e COUTURIER, 2002).

A determinação das estratégias a serem adotadas em um programa de melhoramento genético de plantas é fortemente influenciada pela biologia reprodutiva da espécie. Desta maneira, a possibilidade de cruzamento entre progenitores selecionados requer o conhecimento da variação da receptividade estigmática nos indivíduos a serem cruzados e do período em que a porção feminina encontra-se receptiva ao grão-de-pólen. No caso da A. mearnsii tem se observado uma produção de sementes inferior ao esperado, baixa viabilidade das sementes e anormalidades como o albinismo em plântulas. Esses fatos revelaram a necessidade de intervenção humana nos cruzamentos e a definição de estratégias para o programa de melhoramento genético da espécie.

O presente estudo objetivou analisar a receptividade de estigmas e a viabilidade de políades em inflorescências de A. mearnsii em diversas fases da antese através de método de colorimetria. Também foi analisada a variação na receptividade de estigmas em árvores de A. mearnsii, enriquecendo as informações sobre a 
biologia reprodutiva da espécie e fornecendo subsídios para que estratégias de controle dos cruzamentos sejam realizadas.

\section{MATERIAL E MÉTODOS}

\subsection{Material vegetal}

No período do florescimento em outubro de 2003 foram colhidos galhos contendo inflorescências em 20 árvores de $A$. mearnsii da APS da Fazenda Locatelli, pertencente à empresa SETAS.A., localizada no município de Butiá (RS). As 20 árvores com os seus respectivos galhos foram individualizados e codificados: 03, 04, 05, 06, 08, 28, 29, 30, 31, 32, 33, 40, 41, 42, 44, 45, 46, 47, 48 e 49. A coleta foi realizada no início da manhã. Os galhos tiveram a base parafinada para evitar a desidratação e foram imediatamente transportados para o Laboratório de Biotecnologia Florestal (Universidade Federal de Santa Maria, Santa Maria, RS), local em que as análises foram realizadas.

\subsection{Procedimento de colorimetria e condições para a análise da receptividade de estigmas e viabilidade de políades}

O método de colorimetria utilizado foi o reagente de Baker (RODRIGUEZ-RIANO e DAFNI, 2000), o qual detecta a presença de atividade da enzima álcool desidrogenase. Essa solução contém em sua formulação água destilada e tampão fosfato $0,1 \mathrm{M}, \mathrm{pH} 7,3( \pm 0,2)$ na relação de 2:1; Nitroblue Tetrazólio(NBT); Nicotinamida Adenina Dinucleotídio (NAD), 0,9mM e etanol 50\%.

Os estigmas foram excisados das inflorescências com o auxílio de uma tesoura e prontamente espalhados em lâminas de vidro em que se adicionou $25 \mu \mathrm{L}$ do reagente de Baker(RODRIGUEZ-RIANO e DAFNI, 2000). As anteras foram excisadas das inflorescências e colocadas para secar em temperatura ambiente por um período de duas horas com a finalidade de liberação das políades de seu interior. As políades foram espalhadas sobre lâminas de vidro com o auxílio de um pincel fino, sobre as quais foram adicionados $25 \mu \mathrm{L}$ da solução de coloração. As lâminas de vidro foram postas para incubar em estufa por 15 minutos a $25^{\circ} \mathrm{C}$ e, após, levadas para secar em temperatura ambiente.

As amostras foram fixadas em glicerol, avaliadas em microscopia óptica e registradas com o auxílio de uma máquina fotográfica analógica acoplada em um microscópio óptico. A coloração azul verificada em estigmas indicou a receptividade e em políades, a viabilidade. A ausência de coloração em estigmas e políades revelou a ausência de receptividade e de viabilidade, respectivamente.

\subsection{Receptividade de estigmas e viabilidade de políades de $A$. mearnsii na antese}

A receptividade de estigmas e a viabilidade de políades foram analisadas em diversos estágios de abertura floral. Para a obtenção dos estigmas e das políades, as inflorescências foram selecionadas de acordo com cinco categorias de abertura floral: i) início da antese (25\% de flores abertas por inflorescência); ii) inflorescências em antese (26\% a 75\% de flores abertas por inflorescência); iii) inflorescências completando e em total antese (76\% a $100 \%$ de flores abertas por inflorescência); iv) início da senescência (inflorescências com sinais visíveis de perda do vigor floral) e v) em adiantado estado de senescência (inflorescências secas).

Para a análise da receptividade em diversas fases da antese foram utilizados $25 \mu \mathrm{L}$ do reagente de Baker (RODRIGUEZ-RIANO e DAFNI, 2000) em lâminas de vidro contendo uma mistura de estigmas das árvores amostradas na APS. O delineamento utilizado foi inteiramente casualizado composto por cinco tratamentos distribuídos em duas repetições constituídos de estigmas obtidos de inflorescências das 20 árvores de A. mearnsii anteriormente citadas que se encontravam nos estágios de antese descritos.

Para analisar a viabilidade polínica durante os diversos estágios da antese utilizou-se uma mistura de políades das árvores amostradas na APS. As políades foram espalhadas sobre lâminas de vidro contendo $25 \mu \mathrm{L}$ do reagente de Baker (RODRIGUEZ-RIANO e DAFNI, 2000). Foi utilizado o delineamento inteiramente casualizado composto por cinco tratamentos distribuídos em duas repetições contendo políades obtidas de inflorescências das 20 árvores da APS. Cada tratamento consistiu em amostras de políades obtidas de inflorescências em diversos estágios de abertura floral.

A verificação das hipóteses foi realizada através do teste de independência do $\chi^{2}$ (Qui-quadrado) em nível de significância de 5\%. Foi considerada como hipótese $H_{o}$ a ausência de diferença significativa $(p \geq 0,05)$ de receptividade estigmática e de viabilidade entre as políades com o decorrer da abertura floral.

R. Árvore, Viçosa-MG, v.32, n.4, p.609-616, 2008 


\subsection{Receptividade de estigmas de árvores de $A$. mearnsii de APS}

Foram selecionadas inflorescências frescas e no auge do vigor floral para a obtenção dos estigmas que foram excisados com o auxílio de uma tesoura e espalhados sobre lâminas de vidro, em que foram adicionados $25 \mu \mathrm{L}$ do reagente de Baker (RODRIGUEZRIANO e DAFNI, 2000). O procedimento para incubação das lâminas, secagem e avaliação foi descrito no segundo item da metodologia. Para padronizar o material vegetal estudado, as inflorescências em estágio de senescência e em início de abertura floral foram descartadas.

O delineamento utilizado foi inteiramente casualizado composto por 20 tratamentos constituídos de estigmas obtidos das árvores da APS distribuídos em duas repetições. Foi considerada como hipótese $\mathrm{H}_{\mathrm{o}}$ a ausência de diferença significativa ( $\mathrm{p} \geq 0,05)$ na receptividade estigmática entre as árvores amostradas na APS. A verificação das hipóteses foi realizada através do teste de independência do $\chi^{2}$ (Qui-quadrado) em nível de significância de 5\%.

\subsection{Análise estatística}

Para testar as hipóteses descritas anteriormente foi utilizado o teste do $\chi^{2}$ (Qui-quadrado) de associação (ou teste de independência) para verificar a correlação entre variáveis categóricas, em que o único total fixo é o total de indivíduos estudados. $\mathrm{O} \chi^{2}$ foi calculado de acordo com a Equação 1.

$$
\chi^{2}=\frac{\sum d^{2}}{\lambda}
$$

em que:

d = desvio entre as freqüências observadas e esperadas;

$\boldsymbol{\lambda}=$ freqüências esperadas.

O cálculo das freqüências esperadas $(\boldsymbol{\lambda})$ foi realizado de acordo com a seguinte Equação:

$$
\lambda=\frac{T C \times T L}{T G}
$$

em que:

$$
\begin{aligned}
& \text { TC = total de observações na coluna; } \\
& \text { TL = total de observações na linha correspondente; } \\
& \text { TG = total geral de observações. }
\end{aligned}
$$

Para realizar a comparação entre as hipóteses $\mathrm{H}_{\mathrm{o}}$, em que as proporções observadas e esperadas foram consideradas iguais em nível de significância de 5\% e $\mathrm{H}_{1}$, pela qual as proporções observadas diferiram das proporções esperadas, realizou-se o cálculo do $\chi^{2}$ crítico, obtido do grau de liberdade calculado de acordo com a seguinte Equação:

$$
\mathrm{GL}=(\mathrm{L}-1) \times(\mathrm{C}-1)
$$

em que:

$$
\begin{aligned}
& \mathbf{L}=\text { número de categorias-linha; } \\
& \mathbf{C}=\text { número de categorias-coluna. }
\end{aligned}
$$

De acordo com este critério de comparação, quando os valores do $\chi^{2}$ crítico foram inferiores ao $\chi^{2}$ calculado, os desvios entre as proporções observadas e esperadas foram considerados significativos em nível de significância de 5\% e rejeitou-se a hipótese $\mathrm{H}_{\mathrm{o}}$, pela qual as proporções observadas e esperadas foram consideradas iguais. Quando os valores do $\chi^{2}$ crítico foram maiores que o $\chi^{2}$ calculado, os desvios entre as proporções observadas e esperadas foram considerados não-significativos em nível de significância de $5 \%$ e se aceitou a hipótese $\mathrm{H}_{\mathrm{o}}$ em que as proporções observadas e esperadas foram consideradas iguais (receptividade estigmática uniforme).

\section{RESULTADOS E DISCUSSÃO}

\subsection{Receptividade de estigmas e viabilidade de políades de A. mearnsii em diversos estágios de antese}

Através de observações prévias realizadas em condições de laboratório, verificou-se que a abertura completa das flores foi atingida, em média, em 25 horas e os sinais de senescência foram observados 70 horas depois de completada a antese. O resultado verificado em A. mearnsii diferiu daquele obtido por Tandon et al. (2001) ao estudarem $A$. senegal. onde observaram in vivo que as inflorescências levaram um período de aproximadamente duas horas no início da manhã para a completa abertura floral. Ao estudarem a biologia da polinização do híbrido A. mangium x A. auriculiformis, Sornsathapornkul e Owens (1998) observaram que a antese ocorreu sincronicamente entre os botões florais, quando a abertura floral plena foi atingida em cinco a seis horas e os sintomas de senescência foram percebidos em grande parte das flores aproximadamente 430 horas após a antese. Os estigmas tornaram-se receptivos um dia após a completa abertura floral e 
os autores observaram que esses se tornaram escuros após 48 horas da antese.

Através do teste do $\chi^{2}$ de associação rejeitouse a hipótese da receptividade de $A$. mearnsii não apresentar diferenças significativas entre as fases de abertura floral consideradas (Tabela 1). O valor do $\chi^{2}$ calculado foi de 21,8 (p<0,05). Observou-se com a análise da maturidade dos estigmas através do método de colorimetria, durante as fases que precederam à abertura floral, que houve um aumento da receptividade de estigmas à medida que as inflorescências completaram a antese. Durante a fase inicial da antese ( 0 a $25 \%$ de flores abertas), foi observado que $71 \%$ dos estigmas encontravam-se receptivos. Com o progresso da abertura floral até a fase de completa antese, bem como no período em que se iniciaram os sinais de senescência floral, foi observado que $100 \%$ dos estigmas foram coloridos pela técnica, indicando receptividade. Na fase de senescência a porcentagem de estigmas coloridos foi reduzida para $50 \%$, indicando o decréscimo da receptividade.

A viabilidade de políades de $A$. mearnsii diferiu significativamente $(\mathrm{p}<0,05)$ pelo teste do $\chi^{2}$ durante as fases de abertura floral analisadas. Na fase inicial da antese, foi verificado que cerca de $77 \%$ das políades foram coloridas pelo reagente de Baker (RODRIGUEZRIANO e DAFNI, 2000), indicando viabilidade. Com o progresso da abertura floral e na fase de máxima antese, 88\% das políades foi considerado viável. Ao iniciarem os sinais de senescência, a porcentagem de políades coradas de azul diminuiu para $25 \%$. No estado de plena senescência floral, cerca de $23 \%$ das políades de $A$. mearnsii foram consideradas viáveis.

A protoginia em A. mearnsii foi considerada como um dos mecanismos pelo qual a espécie aumenta as chances de polinização cruzada, pois a fase feminina torna-se apta à fecundação antes da liberação de grãos-de-pólen viáveis (GRANT et al., 1994), contribuindo com a polinização cruzada (MALLICK, 2001). A técnica coloriu estigmas e políades em todas as fases da antese analisadas, indicando, respectivamente, receptividade e viabilidade. A maior freqüência de estigmas e de políades coloridos pela técnica foi verificada na fase de máxima abertura floral, sugerindo a sobreposição das fases feminina e masculina. As observações realizadas no presente estudo indicaram que a presença de estigmas receptivos e de políades viáveis em fases idênticas de abertura floral em flores hermafroditas de A. mearnsii estão contribuindo com o aumento da autopolinização pela sobreposição das fases.

Estudos indicaram que a acácia-negra exibe barreiras eficientes à autopolinização em populações australianas (KENRICK e KNOX, 1989). A possibilidade de autopolinização no em Acacia foi sugerida em estudo da biologia reprodutiva em espécies de acácias africanas, entre elas, $A$. tortilis, A. nilotica, A. senegal e A. albida (TYBIRK, 1993). Entretanto, a produção de sementes autofecundadas foi baixa em virtude dos mecanismos de autoincompatibilidade.

Tabela 1 - Acacia mearnsii De Wild - teste do Qui-quadrado $\left(\chi^{2}\right)$, receptividade de estigmas e da viabilidade de políades em diversas fases de abertura floral

Table 1 - Acacia mearnsii De Wild. - Qui-square $\left(\chi^{2}\right)$ analysis of stigma receptivity and the polyad viability in diverse floral opening phases

\begin{tabular}{|c|c|c|c|c|c|c|c|c|c|c|}
\hline \multirow[t]{2}{*}{$\begin{array}{l}\text { Fases da } \\
\text { abertura floral }\end{array}$} & \multicolumn{2}{|c|}{$\begin{array}{l}\text { Quantidade } \\
\text { em número }\end{array}$} & \multicolumn{2}{|c|}{$\begin{array}{c}\text { Freqüências } \\
\text { observadas }\end{array}$} & \multicolumn{2}{|c|}{$\begin{array}{l}\text { Freqüências } \\
\text { esperadas }\end{array}$} & \multicolumn{2}{|c|}{$\begin{array}{l}\text { Desvios entre } \\
\text { as freqüências }\end{array}$} & \multirow{2}{*}{$\begin{array}{c}\text { \% de } \\
\text { estigmas } \\
\text { coloridos }\end{array}$} & \multirow{2}{*}{$\begin{array}{c}\text { \% de } \\
\text { políades } \\
\text { coloridas }\end{array}$} \\
\hline & \multicolumn{2}{|c|}{ Estigmas Políades } & \multicolumn{2}{|c|}{ Estigmas Políades } & \multicolumn{2}{|c|}{ EstigmasPolíades } & \multicolumn{2}{|c|}{ EstigmasPolíades } & & \\
\hline Início da antese & 7 & 168 & 5 & 129 & 6,3 & 136,9 & $\pm 1,3$ & $\pm 7,9$ & 71,4 & 76,8 \\
\hline Inflorescências em antese & 11 & 296 & 11 & 260 & 9,9 & 241,2 & $\pm 1,1$ & $\pm 18,8$ & 100,0 & 87,8 \\
\hline $\begin{array}{l}\text { Inflorescências } \\
\text { completando e } \\
\text { em total antese }\end{array}$ & 14 & 345 & 14 & 303 & 12,6 & 281,2 & $\pm 1,4$ & $\pm 21,8$ & 100,0 & 87,8 \\
\hline Início da senescência & 18 & 12 & 18 & 3 & 16,1 & 9,8 & $\pm 1,9$ & $\pm 6,8$ & 100,0 & 25,0 \\
\hline Senescência & 8 & 44 & 4 & 10 & 7,2 & 35,9 & $\pm 3,2$ & $\pm 25,9$ & 50,0 & 22,7 \\
\hline Total & 58 & 865 & 52 & 705 & - & - & - & - & 89,6 & 81,5 \\
\hline $\begin{array}{l}\text { Receptividade de estigmas } \\
\text { Viabilidade de políades }\end{array}$ & & & $\begin{array}{c}\chi^{2} \text { calcu } \\
21,8 \\
145,7 \\
\end{array}$ & & $\begin{array}{r}\chi^{2} \text { crític } \\
9,48 \\
9,48\end{array}$ & & & & & \\
\hline
\end{tabular}

$(* *)$ - desvio entre as freqüências observadas e freqüências esperadas significativo em nível de 5\% de significância. 
Em outras espécies a possibilidade da fase feminina receptiva coincidir com a fase de viabilidade masculina foi observada. Em Myrciaria dubia (Myrtaceae), uma espécie de porte arbustivo, a ocorrência de sobreposição das fases feminina e masculina pode ter conduzido à autopolinização, mesmo exibindo a protoginia (MAUÉS e COUTURIER, 2002). O método de avaliação da receptividade dos estigmas e da viabilidade polínica utilizado naquele estudo foi de colorimetria, através do reagente de Baker (RODRIGUEZ-RIANO e DAFNI, 2000).

Ao analisarem a biologia reprodutiva de Sterculia urens, Sunnichan et al. (2004) observaram que os estigmas atingiram a máxima receptividade no decorrer da antese. Entretanto, dois a três dias antes da completa abertura floral já havia sinais de receptividade estigmática, indicado pela atividade da enzima esterase, detectada através da utilização de á-naftilacetato como substrato para a detecção de esterases nãoespecíficas ativas em estigmas.

Em Boswellia serrata, a receptividade dos estigmas em diversos estágios da antese (48 horas antes do início da antese até 48 horas após o final da antese) foi verificada através de polinizações controladas (SUNNICHAN et al., 2005), em estudo da biologia reprodutiva dessa espécie arbórea. Os estigmas foram considerados receptivos após 24 horas da antese, indicado pela adesão e germinação dos grãos-de-pólen. Os autores verificaram que a baixa produção de frutos foi resultado da deposição de pólen em estigmas receptivos, sendo estas plantas portadoras de genes para autoincompatibilidade gametofítica. Este fenômeno, de acordo com os autores, tem sido observado em outras espécies polinizadas por insetos, como é o caso de A. mearnsii.

\subsection{Receptividade de estigmas entre árvores de $A$. mearnsii de APS}

Através do teste do $\chi^{2}$, constatou-se que a receptividade de estigmas de $A$. mearnsii encontrouse uniformemente distribuída entre as vinte árvores selecionadas na APS. O valor calculado do $\chi^{2}$ foi igual a 14,04 e do $\chi^{2}$ crítico, igual a 30,14 (Tabela 2). De acordo com os critérios de comparação do $\chi^{2}$ de associação, quando o valor do $\chi^{2}$ calculado for menor que o valor do $\chi^{2}$ crítico se aceita a hipótese $\mathrm{H}_{\mathrm{o}}$. Assim, o desvio entre as freqüências observadas e as freqüências esperadas não foi significativo em nível de 5\% de significância. A técnica coloriu 100\% de estigmas em
17 árvores, 3, 4, 5, 6, 8, 29, 30, 31, 32, 33, 40, 41, 42, 44, 45, 46 e 49, evidenciando a sua receptividade. $\mathrm{Na}$ árvore 28 foram observados 90\% dos estigmas coloridos pela técnica e nas árvores 47 e 48 a porcentagem de estigmas considerados receptivos foi inferior a $90 \%$.

As análises sugeriram que a receptividade de estigmas de $A$. mearnsii não foi influenciada pelos genótipos analisados, pois não foi observada diferença significativa na receptividade do germoplasma analisado. Estudos paralelos têm sugerido que a germinação in vitro de políades de acácia-negra sofre influência dos genótipos. Em estudo com Prunus avium (HEDHLY et al., 2005) foi observada a interação entre os genótipos e a temperatura do ambiente no desempenho dos grãosde-pólen analisados, bem como a influência do receptáculo feminino no desenvolvimento de tubos polínicos in vivo, provavelmente devido às condições nutricionais dos genótipos femininos, ocorrência de autoincompatibilidade gametofítica ou evidências de interação genética.

Aparentemente, na acácia-negra os fatores ambientais parecem ter maior importância na receptividade estigmática. Os processos de adesão, penetração e germinação dos grãos-de-pólen em estigmas receptivos são influenciados tanto por fatores ambientais, tais como a temperatura (HEDHLY et al., 2003), quanto pelas condições estruturais, fisiológicas e citoquímicas do gametófito feminino (BHATTACHARYA e MANDAL, 2004). A interação eficiente desses fatores foi considerada importante para a efetivação da reprodução sexual e a formação de sementes (BHATTACHARYAe MANDAL, 2004).

A receptividade sincrônica observada em árvores de A. mearnsii em plena atividade reprodutiva sugeriu que a produção de gametas femininos viáveis não representa uma barreira à produção de sementes. A baixa produção de sementes poderia encontrar-se vinculada às barreiras preventivas da autopolinização já relatadas para A. mearnsii por Kenrick e Knox (1989) e para outras espécies de acácias (TYBIRK, 1993; TANDON et al., 2001), uma vez que genótipos autoincompatíveis seriam habilitados ao reconhecimento e rejeição de grãos-de-pólen autocompatíveis com conseqüente decréscimo da produção de sementes (PORCHER e LANDE, 2005). 
Tabela 2 - Acacia mearnsiir teste do $\chi^{2}$ (Qui-quadrado) - receptividade de estigmas pelo método de colorimetria em árvores de uma APS.

Table 2 - Acacia mearnsii Chi-square $\left(\chi^{2}\right)$ analysis of stigma receptivity observed by the colorimeter method in trees of the Seed Production Área

\begin{tabular}{|c|c|c|c|c|c|}
\hline \multirow[t]{2}{*}{ Árvores } & \multirow[t]{2}{*}{$\begin{array}{c}\text { Quantidade de } \\
\text { estigmas analisados }\end{array}$} & \multicolumn{2}{|c|}{$\begin{array}{c}\text { Freqüência de } \\
\text { estigmas coloridos }\end{array}$} & \multirow[t]{2}{*}{$\begin{array}{l}\text { Desvio entre } \\
\text { as freqüências }\end{array}$} & \multirow{2}{*}{$\begin{array}{l}\text { Porcentagem de } \\
\text { estigmas } \\
\text { receptivos }\end{array}$} \\
\hline & & Observada & Esperada & & \\
\hline 29 & 10 & 10 & 9,73 & 0,27 & 100 \\
\hline 5 & 6 & 6 & 5,84 & 0,16 & 100 \\
\hline 28 & 10 & 9 & 9,73 & 0,73 & 90 \\
\hline 3 & 9 & 9 & 8,76 & 0,24 & 100 \\
\hline 31 & 5 & 5 & 4,86 & 0,14 & 100 \\
\hline 30 & 6 & 6 & 5,84 & $\pm 0,16$ & 100 \\
\hline 32 & 6 & 6 & 5,84 & 0,16 & 100 \\
\hline 8 & 8 & 8 & 7,78 & 0,22 & 100 \\
\hline 33 & 4 & 4 & 3,89 & 0,11 & 100 \\
\hline 4 & 7 & 7 & 6,81 & 0,19 & 100 \\
\hline 44 & 11 & 11 & 10,7 & 0,30 & 100 \\
\hline 42 & 10 & 10 & 9,73 & 0,27 & 100 \\
\hline 6 & 8 & 8 & 8,76 & 0,76 & 100 \\
\hline 46 & 7 & 7 & 6,81 & 0,19 & 100 \\
\hline 45 & 6 & 6 & 5,84 & 0,16 & 100 \\
\hline 41 & 6 & 6 & 5,84 & 0,16 & 100 \\
\hline 49 & 5 & 5 & 4,86 & 0,14 & 100 \\
\hline 40 & 7 & 7 & 6,81 & 0,19 & 100 \\
\hline 48 & 8 & 7 & 7,78 & 0,78 & 88 \\
\hline 47 & 7 & 6 & 6,81 & 0,81 & 86 \\
\hline \multirow[t]{2}{*}{ Totais } & 146 & 143 & - & - & 98 \\
\hline & & & $\chi^{2}$ calculado & $\chi^{2}$ crítico & \\
\hline Receptiv & & & 14,04 ns & 30,14 & \\
\hline
\end{tabular}

ns - desvio entre as proporções esperadas e observadas não significativo ( $\mathrm{p} \leq 0,05)$.

De acordo com o presente trabalho, há a possibilidade de autofecundação no germoplasma analisado, pela sobreposição da fase feminina receptiva com a fase de viabilidade polínica em inflorescências contendo flores em diferentes estágios de abertura floral. A restrição na produção de sementes em $A$. mearnsii pode estar ocorrendo em função de barreiras à autofecundação, como por exemplo, grãos-de-pólen carregando em seu genótipo genes para autoincompatibilidade com o genótipo da oosfera, uma vez que há disponibilidade de estigmas receptivos e de políades viáveis durante o período reprodutivo. A contribuição com estigmas receptivos durante o período reprodutivo no germoplasma analisado, não pode ser considerada como barreira à produção de sementes em acácia-negra, visto que não há grande variação na receptividade entre as árvores da APS.

\section{AGRADECIMENTOS}

À Empresa SETA S.A., na pessoa do Engenheiro Florestal Elias Moreira, pelo suporte logistico e financeiro à realização do presente trabalho. Ao Técnico Florestal Dijalmas Pacheco, pelo apoio nos períodos de coleta de material.

\section{REFERÊNCIAS BIBLIOGRÁFICAS}

BHATTACHARYA, A.; MANDAL, S. Pollination, pollen germination and stigma receptivity in Moringa oleifera Lamk. Grana, v.43, n.1, p.48-56, 2004.

CALDEIRA, M.V.W.; NETO, R.M.R.;

SCHUMACHER, M.V. Conteúdo e exportação de micronutrientes em acácia-negra (Acacia mearnsii De Wild.) procedência Batemans Bay (Austrália). Revista Árvore, v.27, n.1, p.9-14, 2003.

R. Árvore, Viçosa-MG, v.32, n.4, p.609-616, 2008 
DAFNI, A.; MAUÉS, M.M. A rapid and simple procedure to determine stigma receptivity. Sexual Plant Reproduction, v.11, n. 3, p.177-180, 1998.

GRANT, J.E.; MORAN, G.F.; MONCUR, M.W. Pollination studies and breeding system in Acacia mearnsii. In: AUSTRALIAN TREE SPECIES RESEARCH IN CHINA, 1994, Camberra. Proceedings... Camberra: ACIAR, 1994. p.165-170.

HEDHLY, A.; HORMAZA, J. I.; HERRERO, M. The effect of temperature on stigmatic receptivity in sweet cherry (Prunus avium L.). Plant, Cell and Environment, v.26, p. 1673-1680, 2003.

KENRICK, J.; KNOX, B. Pollen development and cytochemistry in some Australian species of Acacia. Australian Journal of Botany, v.27, p.413-427, 1979.

KENRICK, J.; KNOX, R.B. Structure and histochemistry of the stigma and style of some Australian species of Acacia. Australian Journal of Botany, v.29, p.733-745, 1981.

KENRICK, J.; KNOX, R.B. Quantitative analysis of selfincompatibility in trees of seven species of Acacia. Journal of Heredity, v.80, p.240-245, 1989.

MALLICK, S.A. Facultative dichogamy and reproductive assurance in partially protandrous plants. Oikos, v.95, n.3, p.533-536, 2001.

MAUÉS, M.M.; COUTURIER, G. Biologia floral e fenologia reprodutiva do camu-camu (Myrciaria dubia (H.B.K.) McVaugh, Myrtaceae) no Estado Pará, Brasil. Revista Brasileira de Botânica, v.25, p.441-448, 2002.

PAULA, K.R. Fatores ambientais e genéticos na produção de sementes de acácia-negra. 2005. 77f. Dissertação (Mestrado em Ciências Florestais)-Universidade Federal do Paraná, Curitiba, 2005.

PAULINO, A.F. et al. Distribuição do sistema radicular de árvores de acácia-negra oriundas de mudas produzidas em diferentes recipientes. Revista Árvore, v.27, n.5, p.605-610, 2003.
PERRANDO, E.R.; MARTINS-CORDER, M.P. Rebrota de cepas de Acacia mearnsii em diferentes idades, épocas do ano e alturas de corte. Pesquisa Agropecuaria Brasileira, v.41, n.4, p.555-562, 2006.

PORCHER, E.; LANDE, R. Loss of gametophytic self-incompatibility with evolution of inbreeding depression. Evolution, v.59, p.46-60, 2005.

RODRIGUEZ-RIANO, T.; DAFNI, A. A new procedure to asses pollen viability. Sexual Plant Reproduction, v.12, p.241-244, 2000.

SORNSATHAPORNKUL, P.; OWENS, J.N. Pollination biology in a tropical Acacia hybrid (A. mangium Willd. x A. auriculiformis A. Cunn. ex Benth). Annals of Botany, v.81, p.631-645, 1998.

STIEHL-ALVES, E.M.; MARTINS-CORDER, M.P. Acacia mearnsii De Wild. (Fabaceae) reproductive biology II: Flowering and fructification phenology. Crop Breeding and Applied Biotechnology, v.6, p.144-150, 2006.

SUNNICHAN, V.G.; MOHAN-RAM, H.Y.; SHIVANNA, K.R. Reproductive biology of Boswellia serrata the source of salai guggul, an important gum-resin. Botanical Journal of the Linnean Society, v.147, p.73-82, 2005.

SUNNICHAN, V.G.; MOHAN-RAM, H.Y; SHIVANNA, K.R. Floral sexuality and breeding system in gum karaya tree, Sterculia urens. Plant Systematics and Evolution, v.244, p.201-218, 2004.

TANDON, R.; SHIVANNA, K.R.; MOHAN-RAM, H.Y. Pollination biology and breeding system of Acacia Senegal. Botanical Journal of the Linnean Society, v.135, p.251-262, 2001.

TYBIRK, K. Pollination, breeding system and seed abortion in some African acacias. Botanical Journal of the Linnean Society, v.112, p.107-137, 1993. 